\title{
Effects and mechanism compositions of micro- biological treatments of antagonists on preservation quality of FengHuang honey peach fruit: A study from a multi-year experiment
}

\author{
Hui Li, Jianlong Li*, Yijia Wang, Yang Li, Xinyu Zhao \\ ${ }^{1}$ College of Life Science, Nanjing University, Nanjing, Jiangsu 210000, China; \\ *Corresponding Author Email:jlli2008@nju.edu.cn, lijianlongnju@163.com.Tel: +86-25-83592715
}

\section{ABSTRACT}

\begin{abstract}
Peaches are rich of nutritive and medicinal value, they are widely grown in the world, but it is not easy to preserve. In order to explore the effects and mechanism of micro-biological preservation methods and find out a neweffective way to preserve peaches which fits the food safety policy, we using antagonists regarded as a potential useful solution for the issue. In this study, three new antagonists, Cryptococcus Laurentii (CL), Candida Guilliermondii (CG) and Tricho-sporon Aquatile (TA) were used and evaluated in preserving peaches. With a multi-year (2011 -2015) study, the treatments with CL, TA showed obvious advantages. After spraying the three antagonists, the decay,rots, respiration,weight loss decreased compared with the CK.The results of this study indicated the beneficial effect of Malon Dialdehyde (MDA), polyphenol oxidase (PPO) and SSC have been reduced by sprayingCL of $10^{8} \mathrm{CFU}$ $\mathrm{ml}$. The TA of $10^{8} \mathrm{CFU} / \mathrm{ml}$ showed most affective results in weight loss and respiration. The peaches were firmer than the $\mathrm{CK}$ with the treatment of $\mathrm{CL}$ of $10^{8} \mathrm{CFU} / \mathrm{ml}$, as well as the reduction ofrelative conductivity. The MDA growth rate of CL treatment was $82.60 \%$ and PPO growth rate was $11.04 \%$ lower than the controlled group. The results indicated the ability of Cryptococcus Laurentii $(C L)$ antagonist is an effective way tocontrol postharvest disease in honey peaches.
\end{abstract}

Keywords: Antagonist yeast, Cryptococcus Laurentii, Trichosporon Aquatile; Candida Guillier-mondii Microbiological methods, Antagonists preservation, Postharvest biological control, Biosafety

\section{INTRODUCTION}

Fenghuang town (Jiangsu, China) is one of the most famous growing areas for peaches, a popular fruit in China. Native peaches from Fenghuang town are famous for their rich nutrition and suitable ratio of sugar to acid as well as their strong flavor. However, peaches have a very short shelf life of less than 3 days at ambient temperature due to their rapid metabolism after harvest (Akhtar et al. 2010; Asgharia and aghdam, 2010). This is due to their higher respiration rate and high susceptibility to chilling injury and fungal decay (Robertson et al., 1990). Their shelf life is limited by weight loss and physiological disorders, as well as internal browning and changes in texture (Fishman et al. 1993). Therefore, cold storage has always been used as the main method to slow these processes to delay the peaches decay, but chilling injury (Cl) limits its peach storage life at low temperatures, such as apples (Lurie et al., 1994), mango (Ketsa et al. 1998), and strawberry (Garcia et al., 1995). Postharvest losses of fruit and vegetables is very common, representing more than $25 \%$ of the total production in industrialized countries and more than $50 \%$ in developing countries.

Meanwhile, with the development of society demands, people become more and more concern about the safety of food. Since the chemical pesticide and antstaling agent are harmful to human beings, especially to children, the use of chemical residue keep drawing the whole focus of society (Fillipi et al. 2008).It is necessary to continue finding new potential micro-organisms to host interactions and increase the potential of bio-control helping to become a real alternative instead of fungicides (Genovese and Lozano (2006).A newly emerging protecting method, the biological prevention and 
cure becomes the main tendency, and the microorganism method, especially the antagonism yeast which is getting out from the surface of the fruits and vegetables showed excellent affect at postharvest among the multitude biological preventions (Overbeek 1977). Because of the excellent antagonism prevention effect, non-toxic and could be applied with chemical bactericide, the yeast become main point in the biological research upon fruits and vegetables (Fillipi et al. 2008). Yeast as a typical antagonism has many advantages, and the most obvious grace is that it can survive on the relatively dry surface of fruits and vegetables. It can also rapid multiply by using nutrition, show broad-spectrum resistance, and have stabilized protection effects (Guiavarch et al. 2005, Zhi et al. 2008).

Cryptococcus Laurentii (CL) has been used as a biological prevention to control the diseases of apples, pears, strawberries, kiwi fruits and pomelos (Boff et al.2003). The research showed that, the suspensions of Candida Guilliermondii (CG) can multiply on the wounded part of honey peaches without producing antibiotics (Liao, $\mathrm{H}$. Met al.2007). Another research manifested that the supernatant fluid of suspensions of TA can effectively inhibit blue mold diseases of apples (Enomoto et al. 1997).Suspensions of TA can rapidly multiple in the wounded part of apples,so it could be fitted with the environment of wounded area. The characteristics of rapid multiply and utilize of nutrition put ascendant power to antagonism between the competitions and the pathogenic bacteria (Lin, H. M et al.1992). Biological method has high security, it avoids the high cost of using physical methods and chemical agents. It can be widely promoted.

In this study, we characterized the physiological and biochemical responses of the 'Fenghuang peaches spay suspensions of $C G$, suspensions of $C L$ and suspensions of $T A$ at ambient temperature $\left(25-28{ }^{\circ} \mathrm{C}\right)$. The effects of treatments on weightless, firmness, total soluble solids content (TSS), relative values of electric conductivity, respiration, MDA, and PPO were examined after treatment. Treatment time and concentration was determined by previous four-year experiments. We presented an overview of postharvest biological control approaches and explored new research possibilities to improve bio-control activity and thus tried to find a safe, economic, effective and suitable treatment for popularization and application. The study

\section{MATERIALS AND METHODS}

\section{Materials and treatments}

The FengHuang honey peach in Zhangjiagang City is the earliest cultivated peach in southern China with more than 100 years' history. The subtropical humid monsoon climate with four distinct seasons and sufficient light provide a suitable natural condition for peaches growing. The annual average temperature is about $15.7^{\circ} \mathrm{C}$ and total rainfall $1167 \mathrm{~mm}$, and the deep and loose yellowbrown soil in this area is rich of soil organic matter. The tree of FengHuang honey peach is about 2-3 meters high with wide and deep root system. Most of fruits ripened in mid-late July and August with about 105 days' growth period, the average weight of fruit is 250 grams.

The fruits (Prunus persica.cv 'BaiHua') were handharvested at the firm-mature stage from a commercial orchard in Zhangjianggang, China. Fruits were transported to the laboratory at Nanjing University on the same day and then selected for uniform size, color and absence of mechanical damage.

\section{Antagonism materials and their treatments}

We used three antagonisms, Crypto-coccus Laurentii (CL), Trichosporon Aquatile (TA) and Candida Guilliermondii (CG), produced from Agricultural Culture Collection of China (ACCC).

After the activations of the three yeasts, some yeast were strikefrom the agar plane to the NYDA plane (nutrition meat soup $8 \mathrm{~g}$, yeast steeping ointment $5 \mathrm{~g}$, glucose 10 $\mathrm{g}$, agar $15 \mathrm{~g}$, water $1000 \mathrm{ml}$ ) cultural 48 hours at $28{ }^{\circ} \mathrm{C}$. Then inoculating loop were dig from the NYDA plan to the $250 \mathrm{ml}$ culture solution, which contained $50 \mathrm{ml}$ $\mathrm{NYDB}$ (which is as same as NYDA, except agar) and cultivated it in a concussion incubator with constant temperature at $28^{\circ} \mathrm{C}$.After 48 hours prepared that culture solution into three disposal fluid:

We pick 7 peaches as one group sprayed of antagonism and sterile water, and make sure that each one has been uniformity covered by the suspensions. The peaches were open-air drying, packing and storing at ambient temperature. After 24 hours, the physical indexes should be measured three times per peach every day, and the whole research should be repeated twice.

\section{Weight loss}

The mass was measured by an MP 2000-2 balance $( \pm 0.05 \mathrm{~g})$ (Shanghai Balance Instruments, China).Weight loss was calculated as: weight loss $=(\mathrm{Wi}-\mathrm{Wf}) / \mathrm{Wl} \times 100 \%$ (Liu et al. 2008).

\section{Fruit firmness}

The firmness of peaches was recorded during storage to determine the shelf life. Firmness values of each individual peach without skin were measured at three points of the equatorial region by using GY-3 firmness 
Table 1. Experimental Design

\begin{tabular}{c} 
CK: the contract: sterile water \\
\hline $\mathrm{CG}: 1 \times 10^{8} \mathrm{CFU} / \mathrm{ml}$ suspensionofCandidaGuilliermondii \\
$\mathrm{CL}: 1 \times 10^{\circ} \mathrm{CFU} / \mathrm{ml}$ suspensionof Cryptococcus Laurentii \\
$\mathrm{TA}: 1 \times 10^{\circ} \mathrm{CFU} / \mathrm{ml}$ suspensionofTrichosporonAquatile \\
\hline
\end{tabular}

tester (Zhejiang Tuopu, China) with an $11 \mathrm{~mm}$ diameter flat probe. The firmness of each peach was measured three times on different sides. Three replicates were used per treatment and the result is the mean of the replicates (Zhou et al. 2009).

\section{TSS}

Measurement of TSS was conducted on juice samples collected from five fruits per treatment, using a Refractometer (WZS-I, Shanghai Optical Instruments, China) and expressed as Brix (Park et al. 2002).

\section{Membrane integrity}

Membrane permeability, expressed by relative relative conductivity rate, was determined using a conductivity meter (Model DDS-11A, Shanghai Scientific Instruments, China). Determination of membrane integrity was carried out according to a modified method (Arreola et al.1991). Nine slices, $10 \mathrm{~mm}$ in diameter and $4 \mathrm{~mm}$ thick, obtained from nine fruits were washed three times in deionized water for about $1 \mathrm{~min}$, dried with filter paper, and put together into $50 \mathrm{ml}$ conical flasks containing $40 \mathrm{ml}$ deionized water. These were then incubated at $25^{\circ} \mathrm{C}$ for $180 \mathrm{~min}$. The resulting solution was then placed in a water bath $\left(100^{\circ} \mathrm{C}\right)$ for $30 \mathrm{~min}$ and cooled to $25^{\circ} \mathrm{C}$ before the final conductivity (total relative conductivity) was measured (Sampedro et al. 2008).

The percentage membrane integrity was calculated as: Membrane integrity $\%=[1$ - (relative conductivity after $180 \mathrm{~min}$ submersion/total relative conductivity)] $\times$ 100(Fang et al. 2006)

\section{Rate of respiration}

Respiration was measured by the rate of $\mathrm{CO}_{2}$ production. In doing this 30 fruits (ten fruit per chamber) from each treatment were sealed in a chamber and air was passed through the chamber(Bradford, M. M 1976). The effluent air was connected to a GXH-3051 (Institute of Junfang Scientific Instrument; Beijing, China) Infrared Gas Analyser (IRGA) and the respiration rates was expressed as $\mathrm{ml} \cdot \mathrm{h}^{-1} \cdot \mathrm{kg}^{-1}$. Three independent replicates were conducted under each treatment (Fraeye et al. 2007,
Blumenkrantz, N. and A sboe-Hansen, G 1973)

\section{Soluble sugar and membrane oxidation}

MDA concentration was measured according to Dhindsa et al with modification. This involved grinding of tissue samples $(2.0 \mathrm{~g})$ in liquid nitrogen and an extract was obtained in $5 \mathrm{~mL} 10 \%(\mathrm{w} / \mathrm{v})$ trichloroacetic acid (TCA). After 15 min centrifugation at $10,000 \mathrm{~g}, 2 \mathrm{~mL}$ aliquot of the supernatant was mixed with $2 \mathrm{~mL} 10 \%$ (w/v) TCA containing $0.6 \%(\mathrm{w} / \mathrm{v})$ thiobarbituric acid (TBA) (Sorrivas, $\mathrm{V}$ et al.2006). The mixture was heated to $100{ }^{\circ} \mathrm{C}$ for 20 min, quickly cooled and centrifuged at $10,000 \times \mathrm{g}$ for 10 min. The supernatant was collected and absorbances at $532 \mathrm{~nm}$ and $450 \mathrm{~nm}$ were then measured in spectrophotometer (Shanghai Jinghua, 756 MC). The MDA concentration was calculated according to the formula:6.45 $\times\left(A_{532}-A_{600}\right)-0.56 \times A_{450}$, and the soluble sugar $=11.7 \times A_{450} \quad$ (Reiter et al. 2003). Three independent replicates were conducted in each treatment.

\section{Determination of the PPO activity}

To measure PPO activities, $2 \mathrm{~g}$ tissue from each 10 fruits was homogenized in $5 \mathrm{ml}$ of $0.1 \mathrm{M}$ phosphate buffer $(\mathrm{pH}$ 6.4) and the supernatant was collected, after centrifugation $\left(10,000 \mathrm{rpm} 15 \mathrm{~min}\right.$ at $\left.4{ }^{\circ} \mathrm{C}\right)$, as enzyme extracts. PPO activity was assayed by adopting the method of Pizzocaro, Torreggiani and Gilardi, based on the oxidation of catechol. The increase in absorbance at $410 \mathrm{~nm}$ against blank (prepared in the absence of enzyme) was automatically recorded at every $30 \mathrm{sec}$ up to $3 \mathrm{~min}$, using a spectrophotometer. One unit (u) of enzyme activity was defined as the amount that caused a change of 0.001 in absorbance per minute (Croak Corredig, 2006).

\section{Data processing and statistical design}

For each combined treatment, the experiment was conducted as a completely randomized design with all the treatments. All statistical analyses were performed with SPSS (SPSS Inc., Chicago, IL, USA) and Microsoft Excel. Data were analyzed by one-way analysis of variance (ANOVA). Mean separations were performed by 


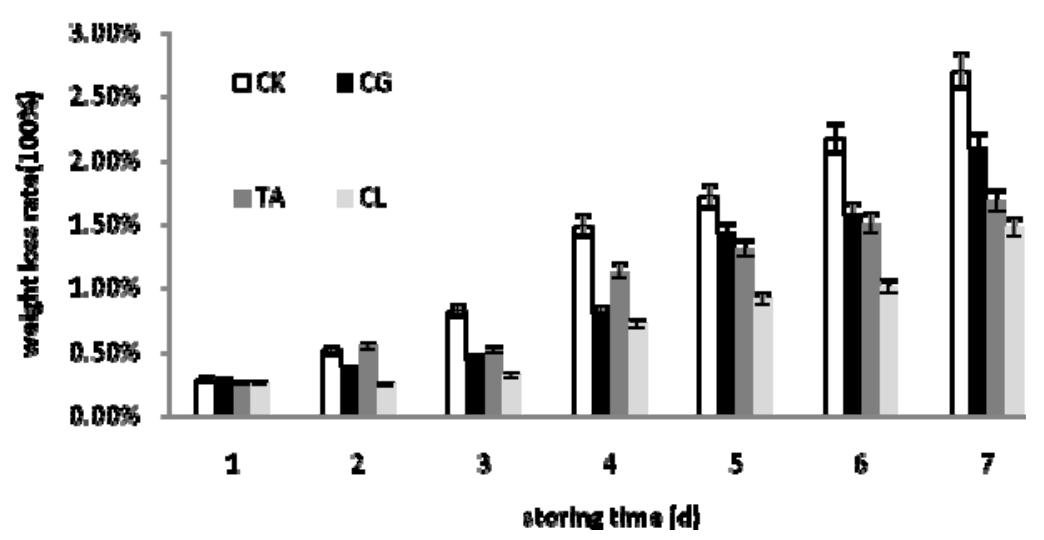

Figure 1. Effect of different treatments on weight loss rate during storage at ambient temperature.

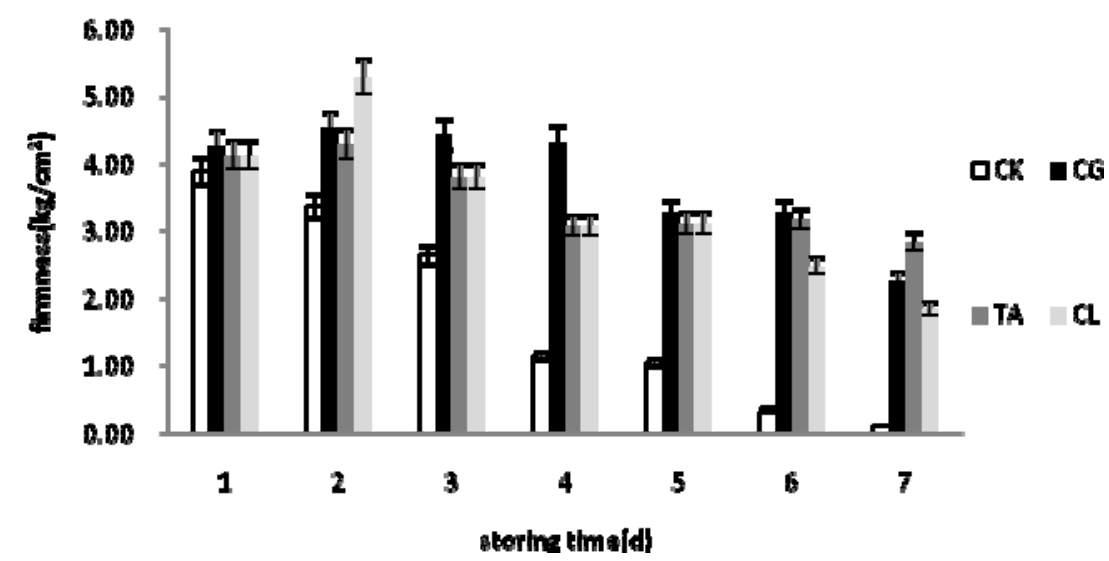

Figure 2. Effect of different treatments on firmness during storage at ambient temperature.

Duncan's multiple range tests. Where significant differences were detected, mean comparisons were done by the L.S.D. test $(P<0.05)$.

\section{RESULTS}

\section{Effects of different treatments on weight loss rate during storage at an ambient temperature}

TA) $1 \times 10^{8} \mathrm{CFU} / \mathrm{ml}$ suspensions of Trichosporonaquatile; CG) $1 \times 10^{8} \mathrm{CFU} / \mathrm{ml}$ suspensions of Candida guilliermondii; CL) $1 \times 10^{8} \mathrm{CFU} / \mathrm{ml}$ suspensions of Cryptococcus laurentii; $\mathrm{CK})$ sterile water.

As shown in Figure1, the weight loss rate of fruit treated with suspensions of CG reduced by $0.175 \%$ after days of storage, which was the lowest among all sets (Figure. 1). The CK recorded maximum weight loss rate of $0.356 \%$. The suspensions $C L$ and $T A$ effectively reduced the weight loss by $0.158 \%, 0.231 \%$ and $0.196 \%$ after $4 \mathrm{~d}$. It was also observed that there was slightly less mass loss of CK than those ones with yeast treatments.
There was no significance difference among all the treatments $(P>0.05)$. The reduction in weight loss rate in suspensions of the yeasts treated fruits might be due to the maintenance of fruit firmness and tissue rigidity by decreasing the enzyme activity responsible for disintegration of cellular structure, which decreases the gaseous exchange (Reiter et al.2003).

\section{Effect of different treatments on firmness during storage at ambient temperature}

Fruit firmness is an important indication of postharvest physiology and quality of fruits during storage. The major changes of softening in peaches involved the catabolism of cell walls and the development of an intercellular matrix containing pectins (Croak and Corredig, 2006). Fruit firmness decreased gradually during storage most likely due to hydrolysis of metabolites. Higher firmness $\left(1.41 \mathrm{~kg} / \mathrm{cm}^{2}\right)$ was observed in fruits treated with suspensions of CG whereas minimum firmness was under control with the same storage period (Figure 2). 


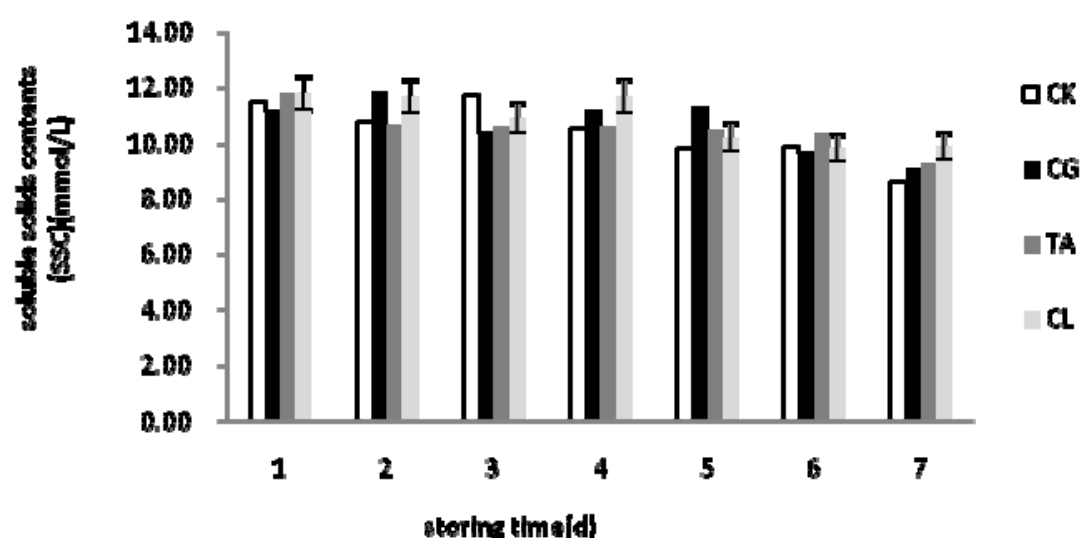

Figure 3.Effect of different treatments on total soluble solids content (SSC) during storage at ambient temperature

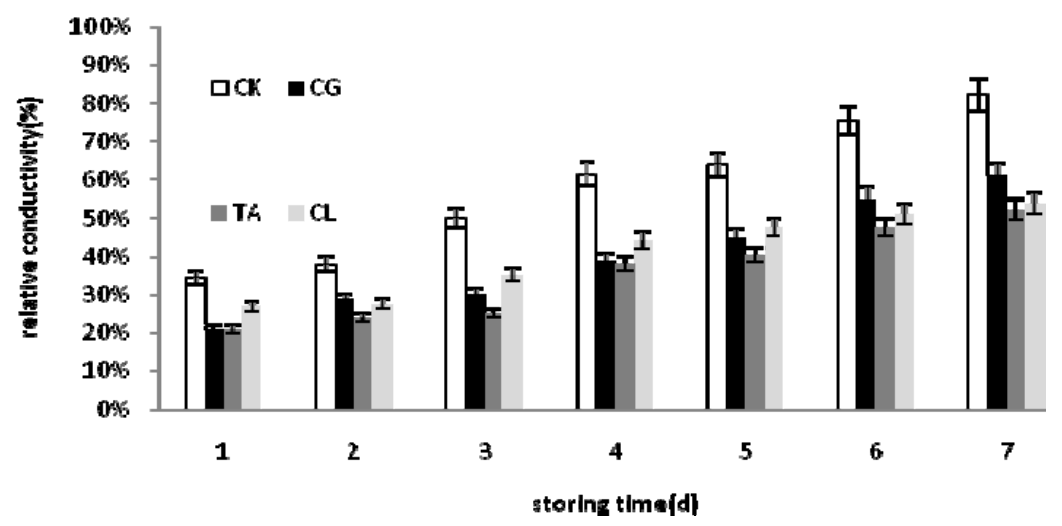

Figure 4.Effectof different treatments on relative conductivity during storage at ambient temperature.

The experimental results showed that the firmness of the CK with an initial firmness of $5.3 \mathrm{~kg} / \mathrm{cm}^{2}$ decreased to $1.84 \mathrm{~kg} / \mathrm{cm}^{2}$ after 3 days of storage, while the firmness ofsuspensions of $C G$ treatment was $3.65 \mathrm{~kg} / \mathrm{cm}^{2}$. It was shown that suspensions of CG, CL and TA were significantly more effective than the CK. It was indicated that the softening of fruit texture had a close relationship with the depolymerisation and solubility of flesh cell wall polysaccharides. Reasonable contents of calcium can retain high levels of ionically-bound pectins and retard the textural degradation (Tomasula et al.1997).

\section{Effect of different treatments on total soluble content(SSC) during storage at ambient temperature}

Soluble solids content (SSC) is an important index for fruit quality evaluation during the storage period (Khorshid et al. 2007).Sugars are the main soluble metabolites, which include glucose, fructose and sucrose in honey peach, comprising $99 \%$ of total sugar content (Calix et al. 2008).
Figure 3 shows the results of different chemical treatments on SSC, indicating that the treatment with CG was the most effective $(p<0.05)$ in maintaining the SSC than the other treatments. At the $7^{\text {th }}$ the SSC of fruits treated with suspensions of $C G, C L$ and $T A$ reduced $11.59 \mathrm{mmol} / \mathrm{L}, 11.48 \mathrm{mmol} / \mathrm{L}, 10.65 \mathrm{mmol} / \mathrm{L}$. The $\mathrm{CK}$ recorded maximum SSC $8.91 \mathrm{mmol} / \mathrm{L}$ at the end of storage. It was indicated that the suspensions of yeast treatment was more effective in maintaining the SSC than the CK.

\section{Effect of different treatments on relative conductivity during storage at ambient temperature}

Relative conductivity is a measure of loss of semipermeability of cell membranes. It can be used as an indicator of membrane damage.It is also widely used as an indicator of the chilling injury (Meyssami et al.1992). As shown in Figure 4, relative conductivity increased during the 6 days of storage. Fruit treated with suspensions of $C G$ treatment was the most effective in 


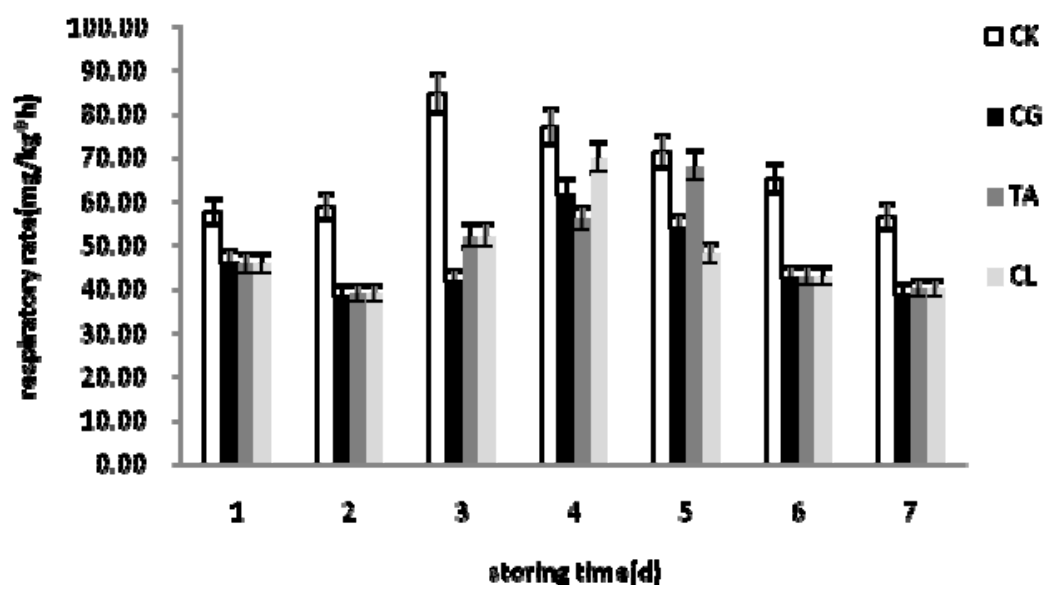

Figure 5.Effect of different treatments on respiration during storage at ambient temperature.

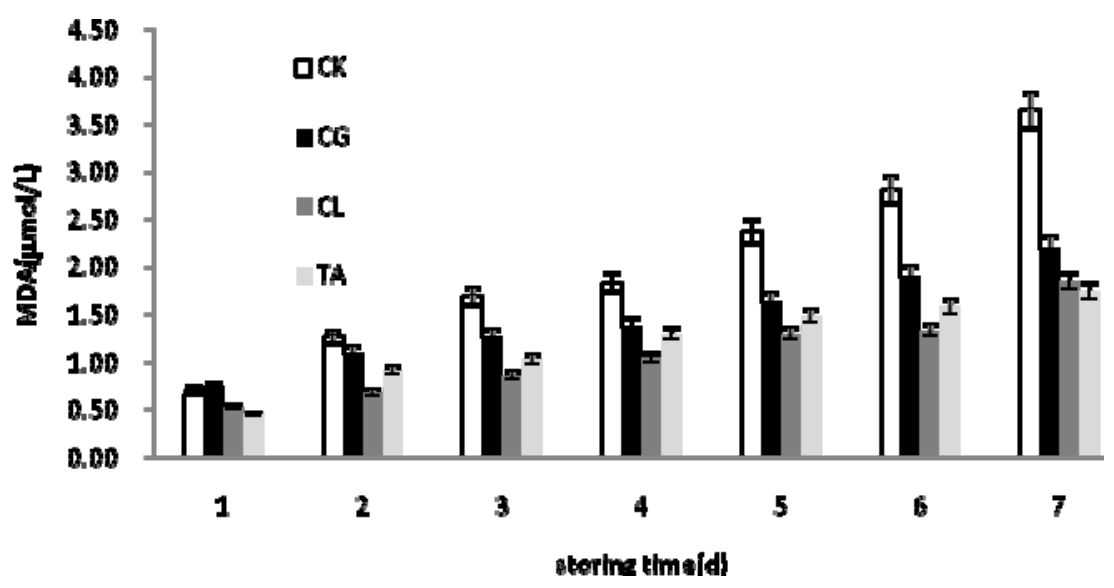

Figure 6. Effect of different treatments on malondialdehyde (MDA) during storage at ambient temperature.

inhibiting the leakage increase. The index increased by $11 \%$ on the $7^{\text {th }}$ day of storage with CG treatment, while the control was $30.8 \%(P<0.05)$. Therelative conductivity of fruits treated suspensions of $C L$ andTA effectively increased by $18.54 \%$ and $21.7 \%$. It is shown that the treatment of suspensions of $C G$ and $C L$ more effective in reducing therelative conductivity than other treatments. The loss of calcium in either pectin molecules or middle lamella can result in fruit softening. It was reported that calciumplays an important role in the stabilization of cell membranes, as fruits softened more with the increase in free calcium in flesh fruits (Tomasula et al. 1997).

\section{Effect of different treatments on respiration during storage at ambient temperature}

Respiration is a major factor contributing to postharvest loss, as it converts stored sugar to energy in the presence of an oxygen substrate, leading to premature senescence (Khorshid et al. 2007). Therefore, it is crucial to maintain the respiration rate at a minimum level as much as possible to prolong the storage life of fruit. The rate of $\mathrm{CO}_{2}$ production of control fruit increased quickly and reached a maximum value on the $6^{\text {th }}$ day and decreased gradually thereafter (Figure5). The respiration of fruits treated with separately, while the suspensions of CG,suspensions of $C L$ and suspensionsof $T A$ reached their respiration peaks by $49.17 \mathrm{ml} \cdot \mathrm{kg}^{-1} \cdot \mathrm{h}^{-1}, 53.25 \mathrm{ml} \cdot \mathrm{kg}^{-}$ ${ }^{1} \cdot \mathrm{h}^{-1}$ and $66.50 \mathrm{ml} \cdot \mathrm{kg}^{-1} \cdot \mathrm{h}^{-1}$ respectively. The respiration rate of the three treatment are better than control group, indicating that suspensions of TA treatment inhibited $\left(26.75 \mathrm{ml} \cdot \mathrm{kg}^{-1} \cdot \mathrm{h}^{-1}\right)$ most effectively.

\section{Effect of different treatments on malondialdehyde (MDA) during storage at ambient temperature}

Espousing can alter the structure of the membranes due to lipid peroxidation. MDA, a secondary end product of 


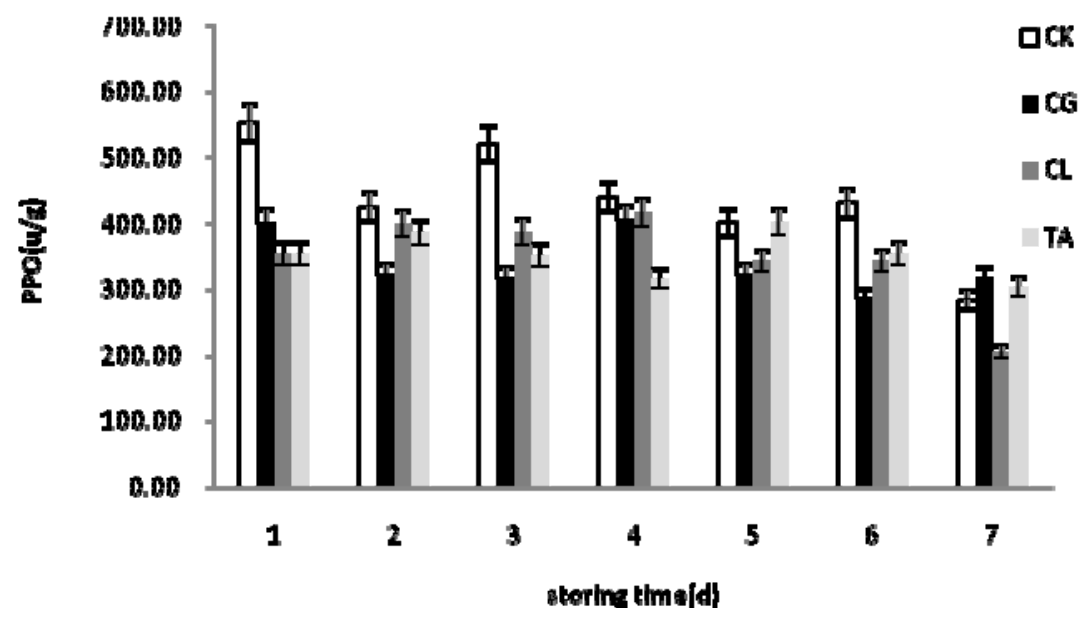

Figure 7. Effect of different treatments on PPO activity during storage at ambient temperature.

polyunsaturated fatty acid oxidation, is thus widely used as an indicator of lipid peroxidation. Changes in MDA levels in a tissue can be a good indicator of the structural integrity of the membranes of plants subjected to low temperature(Ly Nguyen et al. 2003).

As shown in Figure 6, MDA content of control increased gradually within 7 days of storage. Highest MDA (3.73 $\left.\mu \mathrm{mol} \cdot \mathrm{L}^{-1}\right)$ was observed in control fruits after 7 days of storage and minimum MDA $(p<0.05) \quad(2.15$ $\left.\mu \mathrm{mol} \cdot \mathrm{L}^{-1}\right)$ was observed under three treatments of suspensions of CG. The Figures in MDA have raised steadily, suspensions of $C$ Land suspensions of TA. At the end of storage, MDA content in treated fruit was nearly one third lower than that in control fruit.

\section{Effect of different treatments on polyphenol oxidase (PPO) activity during storage at ambient temperature}

The major concern with regard to quality deterioration of peach fruits is flesh browning, which is associated with phenol-related metabolic enzymes POD and PPO. PPO is a key enzyme for enzymatic browning in many fruits. The latent form of PPO is often activated during ripening, senescence or stress condition when the membrane is damaged, which results in an increase of PPO activity (Zhou, L. Y et al.2009). As shown in Figure. 7, PPO activity decreased inconstantly during the storage period. It has also been demonstrated that three combined treatments can inhibit PPO effectively, that PPO decreased gradually over 2 days, then increased and reached maximum values on the $4^{\text {th }}$ day, showing about a 199.3 increase. PPO in the fruits treated with suspensions of CG, increased within 3 days and lowered down afterwards. This change may be related to the stress at the first 3 days of storage, and the inhibition effect appeared later on. Meanwhile, the PPO activities of all treatments were lower than that of the control. Previous work demonstrated that suspensions of CG, suspensions of $C$ Land suspensions of TA markedly inhibited the activities of polyphenol oxidaseof peach, SA treatment delayed activities of PPO of plum fruit and pineapple, and $\mathrm{GA}_{3}$ restrained PPO activity of sweet cherries during storage.

\section{DISCUSSIONS}

\section{Mechanism analysis of different treatments on Fenghuang honey peach}

Calciumions increase the stability of cell walls by binding non-sterifiedpectins and even though plant cell walls are permeable to water, reduced disassembly of this structure might result in higher resistance to water flux, which was demonstrated by the suspensions of CG decreased the rate of fruit weight loss during the preservation period (Kincal 2006).The experimental results showed that the firmness of the CK with an initial firmness of $5.3 \mathrm{~kg} / \mathrm{cm}^{2}$ decreased to $1.84 \mathrm{~kg} / \mathrm{cm}^{2}$ after 3 days of storage, while the firmness ofsuspensions of $C G$ treatment was $3.65 \mathrm{~kg} / \mathrm{cm}^{2}$. It was shown that suspensions of $C G, C L$ and $T A$ were significantly more effective than the CK. It was indicated that the softening of fruit texture had a close relationship with the depolymerisation and solubility of flesh cell wall polysaccharides. Reasonable contents of calcium can retain high levels of ionic ally-bound pectins and retard the textural degradation (Tomasula et al.1997). These results demonstrated that suspensions of CG treatment suppressed the rate of respiration production. It has been demonstrated that suspensions of CG markedly inhibited ethylene production and respiration rate in Bai Hua peach during storage at ambient temperature, suspensions of 
$C L$ effectively delayed the onset of the climacteric peak of respiration, and also inhibited respiration in BaiHua peach during storage. Fruit respiration might have increased in response to fruit damage, and the reduced production of $\mathrm{CO}_{2}$ by calcium-treated blue berries could be associated with reduced tissue disruption (Siebert et al. 1996).

\section{Security analysis of the treatments on Fenghuang honey peach}

We can see that the three new antagonistsu work in a biological way and meet the food safety requirements well. Yeast is widely used in the food industry. We use the three kinds of yeast to Figureht the mold on the surface of peaches. Meanwhile the yeasts we used were stable enough to keep in good condition and safe to human and animals. Yeast is non-toxic, non-mutagenic, odorless, tasteless, and edible (Fuji and shinohare 1986; Kimoto et al. 1997). For it non-toxic, non-mutagenic, odorless, tasteless, and edible, it is safe in the food industry.

\section{CONCLUSIONS}

The activity of a bio-control agent seems to be primarily dependent on its ability to rapidly colonize the wound site and compete for nutrients. This mechanismshould also largely depend on its ability to attach to hyphae of the pathogenand produce cell wall degrading enzymes or volatile compounds, or induce host resistance.

Antibiotic production has been suggested in responsible forbio-control activity of some bacterial and fungal antagonists. The first observation of a potential microbial control of postharvest diseases of citrus fruit was reported by, with the bacteria Bacillus subtilis. This microorganism has been reported as antagonistic of postharvest diseases of fruits. Its biocontrol activity is mainly due to the production ofantifungal compounds, such as antibiotics, predominantly lipopeptides of surfactin, iturinand gramicidin S. Another antagonistic bacterium, Pseudomonas syringae, effective against Penicilliummoulds in citrus fruit, produces syringomycin and Pseudomonas cepacia and Serratiaplymuthica produce pyrrolnitrin. This leads us to the debate whether an antibiotic-producing microorgani-sm should be used in postharvest phase, due to the concern of introducing an antibiotic into food and the possible development of a pathogen resistance (Fillipi et al. 2008, Siebert et al. 1998).

When numbers of the yeast antagonist reached $10^{8}$ CFU/ $\mathrm{ml}$, the diseasescould be mainly controlled.This result further identified that effective bio-control activity of yeast antagonists mainly depends on the number of yeast cells present in the wound site and competition for nutrients has frequently been cited as a mechanism of bio-control by antagonistic yeasts. The results of this study indicated the beneficial effect of MDA, PPO and SSC have been reduced by CG of $10^{8} \mathrm{CFU} / \mathrm{ml}$. The TA of $10^{8} \mathrm{CFU} / \mathrm{ml}$ showed most affective results in weight and respiration. $C L$ of $10^{8} \mathrm{CFU} / \mathrm{ml}$ makes the peaches firmer than the contract.We believe our new, easy-promotional bio-control fungicides solution could effectively control postharvest diseases in honey peaches and thus contribute to the study of fruit post-harvest preservation, as well as the maintenance of its commercial value.

\section{ACKNOWLEDGEMENT}

We are grateful to the chief editor and anonymous reviewers for illuminating comments. This research was mainly supported by "the Suzhou Science and Technology Project of China (SNG201447), the APN Global Change Fund Project ( ARCP2014-06NMY-Li and CAF2015-RR14-NMY-Odeh ), the Jiangsu Province Agricultural Three Renovations Project of China (SXGC [2014]287) and the nutrition physiology, decay mechanism and comprehensive preservation research of Fenghuang water peach in Zhangjiagang City (ZKN1002).

\section{REFERENCES}

Arreola AG, Balaban MO, Marshall MR (1991). Supercritical carbon dioxide effects orange juice.J. Food Sci. (56):1030-1033.

Alonso J, Howell N, Canet W (1997). Purification and characterization of two pectinmethylesterase from persimmon. J. Sci. Food Agric. (75)352-358

Blumenkrantz N, Asboe-Hansen G (1973).New method for quantitative determination of uronicacids. Anal Biochem. (54): 484-489.

Balaban MO, Arreola AG, Marshall M(1997).PeplowA.Inactivation of Pectinesterase in orange juice by supercriticalcarbon dioxide. Food Sci. (56)741-746.

Boff JM, Truong TT, Min DB, Shellhammer TH (2003). Effect ofthermal processing and carbon dioxide-assisted high pressure processing on pect in methylestrase and chemical changes in orange juice. J. Food Sci. (68):1179-1184

Bradford MM (1976).A rapid and sensitive method for the quantitationof microgram quantities of protein utilizing the principle of protein dye binding Anal. Biochem. (72): 248-254.

Croak S, Corredig M (2006). The role of pectin in orange juice stabilization:effect of pectin methylesterase and pectinase activity on the size of cloud particles. Food Hydrocolloids (20):961-965.

Calix TF, Ferrentino G, Balaban MO (2008). Measurement of high pressure carbon dioxide solubility in orange juice, apple juice, andmodel liquid foods. J. Food Sci.(73):439-445.

Dak M, Verma RC, Jaaffrey SNA (2007). Effect of temperature and concentration on rheological properties of "Kesar" mango juice. J. Food Eng. (80): 1011-1015.

Enomoto A, Nakamura K, Hakoda M, Amaya N(1997).Lethal effect of high pressure carbon dioxide on a bacterial spore.J. Ferment. Bioeng. (83):305-307.

Fraeyel, Duvetter T, Verlent I (2007). Comparison of enzymatic deesterification of strawberry andapple pectin at elevated pressure by fungal pectinmethylesterase.Innovative Food Sci. Emerg. Technol. (8)93-101.

Fang ZX, Zhang M, Tao GG (2006). Chemical composition of clarified bayberry (Myri-carubraSieb.etZucc.) juice sediment. J. Agric. Food Chem. 2006(54):7710-7716. 
Fillipi MV, Genovese DB, Lozano JE (2008). Zeta-potential as a way to determine optimal conditions during fruit juice clarification .In Food Engineering: Integrated Appro-aches.Springer:New York.391-397.

Fillipi MV, Genovese DB, Lozano JE (2008). Zeta-potential as a way to determine optimal conditions during fruit juice clarification. Food Engineering:Integrated Approaches. SpringerNew York. 391-397.

Guijarro B, Melgarejo P, Torres R, Lamarca N(2007).Effects of different biological formulations of Penicillium frequentanson brown rot of peach and nectarine. Bio-Control. (42):86-96.

Gell,De Cal A, Torres R, Usall J, Melgarejo P (2012). Relationship between the incidences of latent infections caused by Monilinia spp. and the incidence of brown rot of peach fruit: factors affecting latent infection. Eur J Plant Pathol .487-498.

Genovese DB, Lozano JE (2006).Contribution of colloidal forces to the viscosity and stability of cloudy apple juice. Food Hydrocolloids .(20):767-773.

Guiavarch Y, Segovia O, Hendrickx M, VanLoey A (2005). Thermal and high-pressure inacti-vation of apectin-methylesterase from white grapefruit (Citrus paradisi). Inno-vativeFood Sci.Technol. (6): 363-371.

Khorshid N, Hossain MM, Farid MM (2007). Precipitation of foodprotein using high pressure carbon dioxide. J. Food Eng. 2007(79):12141220.

Kincal D, HillW S, Balaban M, Portier K (2006). A continuous highpressure carbondioxide system for cloud and quality retention in orange juice.J. Food Sci. (71):338-344.

Liu X, Gao Y, Xu H (2008).Impact of highpressurecarbon dioxide combined with thermal treatment ondegra-dation of red beet (Beta vulgaris L.) pigments. J. Agric. FoodChem. (56):6480-6487.

Liao HM, HuX S, Liao XJH (2007). Inactiva-tion of Escherichia coli inoculated into cloudy apple juice exposed todense phase carbon dioxide. Food Microbiol. (117):126-131.

Lin HM, Yang Z, Chen L (1992). F.Inactivation of Saccharomycescerevisiae by supercritical and subcritical carbon dioxide. Biotechnol. Prog. (8):458-461.

Ly Nguyen B, Van Loey AM, Smout C (2003). Effect of mild-heat and high-pressure processingon banana pectin methylesterase: a kinetic study. J. Agric. FoodChem. (51):7974-7979.

Liao HM, Hu XS, Liao XJ (2007). Inactivation of Escherichia coli inoculated into cloudy apple juice exposed to dense phase carbon dioxide. Int. J. Food Microbiol. (117):126-131.

Madrigal C,Pascual S, Melgarejo P (1994). Biolo- gical control of peach twig blight (Monilinialaxa) with Epicocumnigrum. Plant Pathology. (43):554-561.
Meyssami B, Balaban MO, Teixerira AA(1992). Prediction of $\mathrm{pH}$ in model system pressurized with carbon dioxide.Bio-technol. Prog. (8):149-154.

Overbeek JG (1977). Recent developments in the understanding of colloidal stability. J.Colloid Interface Sci. (58):408-422.

Park SJ, Lee JL, Park J(2002). Effects of a combined process of high pressure carbon dioxide and high hydrostatic pressure on the qualityof carrot juice. J. Food Sci. (67):1827-1834.

Reiter M, Stuparic M, Neidhart S (2003). The role of process technology in carrot juice cloud stability. LWT-Food Sci. Technol. (36):165-172.

Sampedro F, Rodrigo D, Hendrickx M (2008). Inactivation kinetics of pectin methyl esterase under combined thermal-high pressure treatment in an orange juice-milk beverage. J. Food Eng. (86):133139.

Sorrivas V, Genovese DB, Lozano JE (2006). Effect of pectinolytic and amylolytic enzymes on apple juice turbidity. J. Food Process. Preserv. (30):118-133.

Siebert KJ, Troukhanova NV, Lynn PY (1996). Nature of polyphenolprotein interactions. J. Agric. Food Chem. (44)80-85.

Tomasula PM, Craig JC, Boswell R (1997). Continuous processfor casein production using high-pressure carbon dioxide. J. FoodEng. (33):405-419.

Zhou LY, Wu JH, Hu XS (2009).. Alterations inthe activity and structure of pectin methylesterase treated by highpressure carbon dioxide. J. Agric. Food Chem. (5):1890-1895.

ZhouL Y, Wang YY, Hu XS (2009). Effect of high pressure carbon dioxide on the quality of carrot juice. InnovativeFood Sci. Emerg. Technol. (10):321-327.

Zhi X, Zhang Y, Hu X (2008). Inactivation ofapple pectin methylesterase induced by dense phase carbon dioxide.J. Agric. Food Chem (56):5394-5400.

Zhou LY, Zhang Y, Hu XS (2009).. Comparisonof the inactivation kinetics of pect in methylesterases from carrot and peach by highpressure carbon dioxide. Food Chem. (115):449-455. 